\title{
ON A NEW MANUFACTURE OF COMPOUND METALLIC RODS AND BARS.
}

At a time like the present, when the high price of Iron is of such importance to the consumers of Rods and Bars, descriptions of iron very extensively employed in many of the staple trades of this neighbourhood, there may be some interest attached to the results of some experiments lately made with the view of producing an economical substitute for solid iron rods and bars, such as are mainly employed in the manufacture of fences, railing, hurdles, metallic bedsteads, and many other purposes.

The specimens now exhibited, though somewhat crude, serve to elucidate the principle of the process.

They are small samples cut from lengths of rods and bars rolled in the following manner :- Two skelps of iron of the requisite weight, previously ascertained, and of the section shown at A, in Fig. 2, Plate 4, are placed togather to form a cylinder, as in Fig. 1 : and two similar skelps, B B, but of a somewhat larger size, are laid round this cylinder in such a manner as to break or cross the joints, as shown in Fig. 1. The whole is then bound together with iron hoops ov strong wire, and a short piece of solid metal driven into one end of this cylinder, which is then filled with sand, earth, or ashes, and well and tightly rammed and dried after which the open end is plugged in the same way as the opposite one had been.

The billet thus charged is put in the furnace, and when at a sufficient heat is removed to the rolls, and rolled out precisely as solid iron; the sand core being reduced in very nearly the same proportion as the iron. The exactness of this proportion depends entirely upon the thorough ramming of the core in the billet, for if the sand be loose, it follows that by the compression of the core in 
rolling, the iron makes up the deficiency in diameter, and a shorter length of rod than the billet was calculated to make is the result. Some of the specimens show this result clearly. The area of sand in the billet shown full size in section in Fig. 13, was one of iron to one of sand, or half sand, but after rolling and reducing it to the size of section in Fig. 14, and nearly 20 feet in length, it was found to have assumed the proportion of one and a half iron to one of sand, or only 2 -5ths sand.

It will be perceived by the specimens, that the sand during the process has become by the heat and great pressure, a semi. vitreous body of exceeding hardness, so close in its texture as to bear a polish; and this appeprs to add (in conjunction with the tubular form of the metallic portion of the rod) very great additional strength;-for upon testing one of the specimens about 5-8ths of an inch in diameter against a length of solid iron rod of the same diameter, by placing both upon benches, and suspending weights from the centre, the compound rod was found to sustain without deflection a wcight that nearly doubled up the solid rod.

Fig. 11 is a section shown half size of a billet 3 inches diameter, made of a single skelp turned up into a cylinder, and containing the same proportion of sand, viz., one half, after being rolled down to the size shown in Fig. 12, 3 inch diameter, the result showed a diminution in the proportion of sand, the finished rod being in the proportion of $1 \frac{1}{2}$ iron to 1 of sand, or 2-5ths area of sand. This was done at the Cwm Avon Wurks in South Wales.

Some of the rods produced have been made from billets turned up into a cylinder from a flat skelp in gun-barrel rolls, and one from the breech end of a twisted gun-barrel; this was of course done merely as an experiment, as it appeared to be the worst description of tube for the purpose; the core however proved as sound as any of the rest. Generally speaking, the form of billet first described appears to be the best, and it is certainly the least expensive.

Thus far the manufacture has been described of round rods. For square rods and flat bars, the same description of billet is employed, varying only in section; thus, for a square rod, a billet 
of the section shown in Fig. 5, composed of two skelps of a $V$ form, as seen in Fig. 6, at FF, will be used; and for a flat bar, the section in Fig. 3, made of skelps of angle iron, as in Fig. 4, would be employed, the operation of rolling being identical with that now in use for solid iron.

It now remains to show the results attained by these experiments, as to the saving of cost in the manufactured rod. The most complete estimate in the possession of the writer is one furnished from the works in South Wales, where the greater portion of these experiments have been made, which is the following:-

Assuming the present price of the rolled skelps of the sections shown, to be

f $\mathrm{s} . \mathrm{d}$.

9100 per ton,

add $2100\left\{\begin{array}{c}\text { per ton, cost of making. ramming, and plugging the } \\ \text { billets, including cost of sand. }\end{array}\right.$ add 100 per ton for contingencies and waste.

\&13 $0 \quad 0$ Total cost of working up one ton of iron into a length

equivalent to that which would be produced from two tons of solid iron; giving the price of the rods or bars containing half sand, $\$ 6$ 10s. per ton measurement, or a saving of about $\$ 3$ for the same length of rod or bar. But it should be remembered that these experiments have been confined to the production of rods not exceeding one inch in diameter, and that as the diameter of the rod increases, a considerably greater proportion of sand than one half can be introduced, consequently a ton of iron may be made to produce more than two tons measurement of the larger rods of bars; this estimate of the saving on an average of all marketable sizes, would therefore be rather within the mark than otherwise.

The samples of rails upon the table, and shown in Figs. 8 and 10, were also rolled at the same works in South Wales, with a view of testing the applicability of the invention to effect a saving of metal in this branch of manufacture.

The piles shown in Figs. 7 and 9, were made in the usual manner, with upper and lower plates of No. 2 iron, the remainder 
being puddled bars, and having a hollow in the centre, for the reception of the core; the sand was in this case first rammed in a core box, $\mathrm{DD}$, made of plate iron, 1 in. thick. In one of these piles the core was 41 inches, in the other, $3 \neq$ inches square, but the ends were left unplugged; the result of the rolling showed that the sand assumed very much the form of the rail, but from the omission of the plugging, the area of the section of sand in the rails, as seen at $\mathrm{SS}$, is not nearly so great in proportion as that of the one introduced in the pile.

Some samples of small copper tubes, made on the same principle as the iron rods, are also shown among the specimens, the only difference in their manufacture being, that the billets were in this case drawn cold, consequently, the sand, not being vitrified, was readily removed afterwards from the bar, leaving it an open tube; but these may be more easily made by charging the billets (the cylinders for which are cast as shown by the specimen exhibited) either with pure silica or plaster of Paris, neither of which will vitrify, and then rolling them hot in the same manner as the iron rods. This kind of core undergoing no change by the action of the fire, may be bored out with ease.

Further experiments are now being made, with the endeavour to produce rod: having a mere skin of iron on the strong core, the result of which the writer will be happy to communicate on a future occasion.

The Crainuan thought the subject of the paper appeared one of considerable interest, and well deserving consideration in connection with the present high price of iron. Some other applications of the plan might perhaps be worth considering, such as the case of long lines of shafting, where it would be useful to obtain great rigidity with a less quantity of iron. The value of the plan would depend much on a uniform regularity being obtained in the position of the sand core in the bars when finished; and be inquired the cause of some irregularity that appeared in the specimens of rails and some of the bars. 
Mr. PAYNE replied that the specimens of rails were the results of only the first experiments, made for the purpose of trying the applicability of the process to such a manufacture, and the practicability of drawing down the sand and iron together under such circumstances. They were imperfect specimens of the process, and the irregularity in the sand core was caused by not having the sand rammed hard enough at the commencement, and not plugging up the ends of the billet. In forming a double-headed rail, it had been intended to introduce a sand core in the centre of each head, extending partly down the stalk of the rail, but separated by about an inch of solid iron in the centre of the stalk, for the purpose of tying the two sides of the metal together. The application of the process to rails had not, however, been considered of so much importance as its use in various forms of bar iron to which it appeared more particu. larly applicable.

The Chalrman thought there would be considerable difficulty in the application of the process to rails, and there would be a danger of their bulging out in the centre, when subjected to the crushing action of the wheels rolling upon them.

Mr. Mathews asked whether the labour of ramming the sand into the pile, could be reduced by any process of running vitrified sand, or other liquid material, into the hollow centre of the pile?

Mr. PAXne replied, that any process of that kind would require a complete tube to be first produced and filled with the material; but that by the present process, the expense of making a tube was avoided, and the skelps were welded together at the time of rolling out the whole; the object was to weld the tube by the same pro. cess as drawing down the compound bar.

Mr. MAY remarked, that the core did not become vitrified in the process, but appeared to remain sand in all the specinens, and this constituted its value in the process; the heat was not sufficient to vitrify the sand, which remained solid, and did not melt or vitrify, but became only more condensed and drawn out in form.

Mr. Fothergill observed, that the cores in many of the specimens were out of the centre, and in any application of the plan to the manufacture of shafting, it would be essential for the core to be 
kept exactly in the centre; if there were any deviation in this respect it would be a serious objection, as the thickness of metal would be unequal, and might be almost cut through where journals were turned down upon the shaft.

Mr. Henry Maddslay suggested, that the shaft might be made solid at the ends if required to be turned down, and. the other bearings made by shrinking on collars to avoid turning down the shaft, according to the present practice in ordinary solid shafting.

Mr. Fotheralli thought there would be a difficulty in regulating the position of any solid parts in the manufacture of the shaft, to provide for turning down in the right place.

Mr. Fenton remarked, that if the core was not truly in the centre, the shaft would be out of balance and lob-sided, causing a very objectionable vibration and unsteadiness at high speeds.

Mr. PAYNE explained, that if the core was truly placed in the billet, it was found to remain quite true throughout the process of rolling. The early specimens shown were imperfect in this respect on account of the imperfection in forming the original billets in the first experiments; but by the present plan the two equal thicknesses of skelp forming the metallic portion of the rod, insured an equal thickness of metal all round, and a true position for the sand core; and in rolling down the bar the thickness of metal was found to be reduced with remarkable uniformity in all parts, so that he thought a correct central position of the core could be insured after some practice in the manufacture.

Mr. CIIFT inquired whether any experiments had been made to test the relative strength of the compound bars and tubes of the same size and thickness? he did not see that the sand core could add materially to the strength of the tube.

Mr. PAYNE replied, that a trial had been recently made of the transverse strength of one of the compound sand-bars $\frac{5}{8}$ inch diameter, compared with a tube of the same thickness of metal, and also a solid rod, all of the same external diameter; but in consequence of a slight inaccuracy in the sizes not being exactly the same, the experiment had not been stated; the result, however, was that the sand-bar was considerably stronger than the hollow tube, and it was also stiffer than the solid rod. 
Mr. EveritT had witnessed the trials in making tubes by this process, but although the result was satisfactory in soundness of tube and uniform thickness of metal, he thought the expense of getting out a sand core would prove too great to allow of manufacturing tubes by this plan. For light bars, such as fencing, where stiffness was the main requisite, the method might be very advantageous, producing a rigid rod at less expense than bar-iron of the same stiffness.

Mr. Mathews asked what proportion of sand was proposed to be employed?

Mr. PAYNE replied, that $\frac{1}{2}$ sand had been hitherto used in the billet, which became reduced by the compression of rolling to about $\frac{2}{6}$ ths sand with $\frac{3}{5}$ ths iron in the finished rod; but it was expected that this proportion of iron would be reduced by further trials to $\frac{1}{2}$, or perhaps less in the finished rod.

The Chairman said, that on a future occasion they would be g'ad to receive the results of the further trial and application of the process; and be proposed a vote of thanks to Mr. Payne, which was passed.

The following paper, by Mr. James Fenton, of Leeds, was then read :- 


\section{COMPOUND METALLIC RODS.}
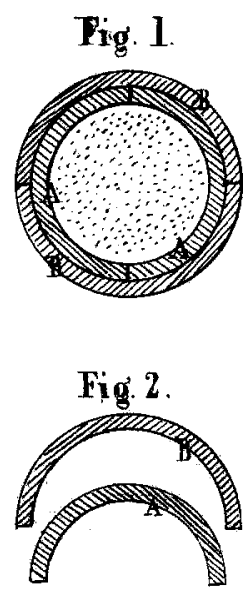

Fig. 3.

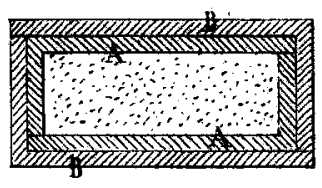

Fig. 4.

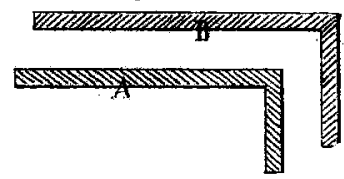

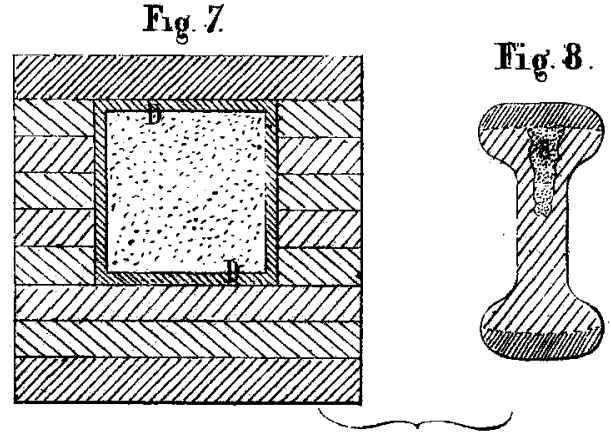

Fig. 9.

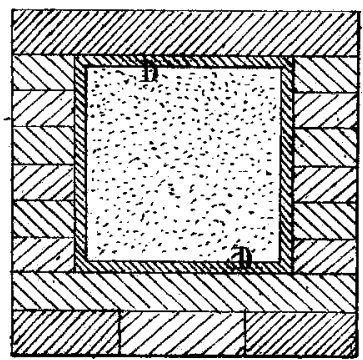

\section{Fig. 10}
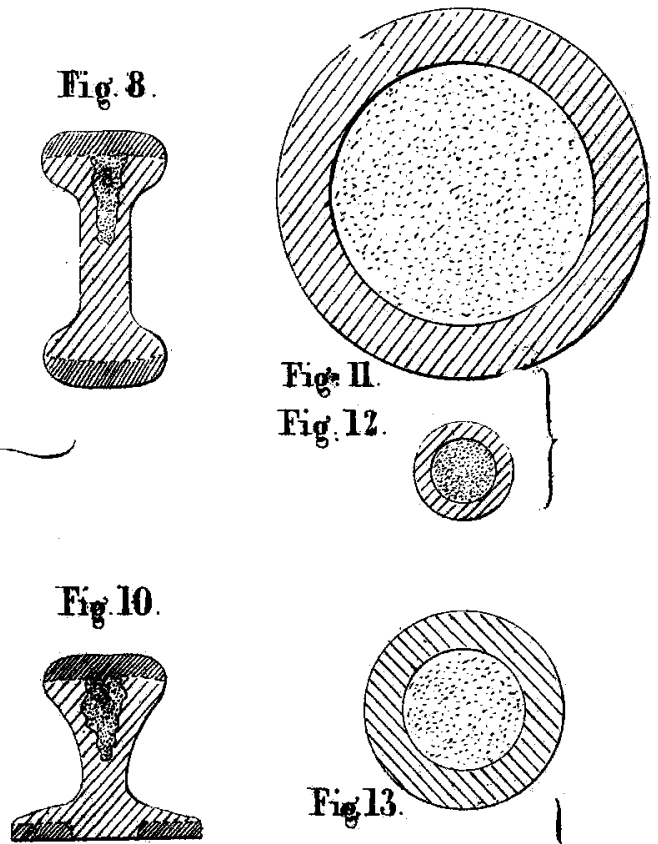

Fig. 6.
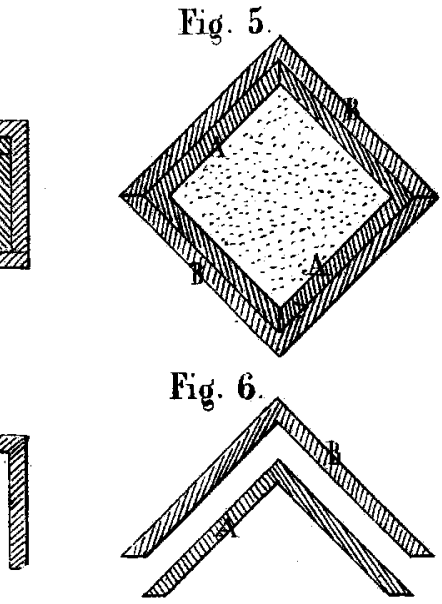

Fige 11

Fig: 12

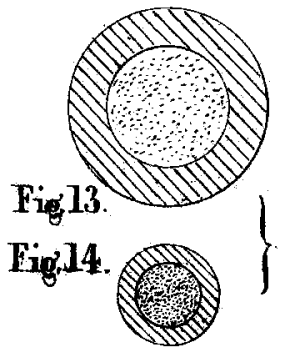

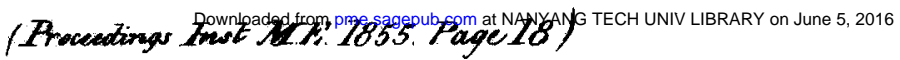

